\title{
COVID-19 and Pregnancy
}

Melania Maria Ramos Amorim 1

https://orcid.org/0000-0003-1047-2514

Alex Sandro Rolland Souza 2

iD https://orcid.org/0000-0001-7039-2052

Adriana Suely de Oliveira Melo 3

(iD) https://orcid.org/0000-0002-8575-544X

Alexandre Magno Delgado 4

https://orcid.org/0000-0002-9310-4196

Anna Catharina Magliano Carneiro da Cunha Florêncio 5

iD https://orcid.org/0000-0003-1281-192X

Thaise Villarim de Oliveira 6

iD https://orcid.org/0000-0002-9194-3797
Lara Caline Santos Lira 7

iD https://orcid.org/0000-0002-8430-6095

Lucas Martins dos Santos Sales 8

iD https://orcid.org/0000-0002-1648-7760

Gabriela Albuquerque Souza 9

iD https://orcid.org/0000-0002-3631-6782

Brena Carvalho Pinto de Melo 10

iD https://orcid.org/0000-0002-7671-2122

Ítalo Morais 11

iD https://orcid.org/0000-0001-7137-4761

Leila Katz 12

iD https://orcid.org/0000-0001-9854-7917

Northeast COVID-19 and Pregnancy Study Group (NCOVIP)*

1,2,4,5,6,10,12 Instituto de Medicina Integral Prof. Fernando Figueira. Rua dos Coelhos, 300. Boa Vista. Recife, PE, Brasil. CEP: 50.070-902. E-mail: profmelania.amorim@gmail.com

3,8 Universidade Federal de Campina Grande. Campina Grande, PB, Brasil.

7 Universidade Estadual da Paraíba. Campina Grande, PB, Brasil.

9 Universidade Católica de Pernambuco. Recife, PE, Brasil.

11 Centro Universitário Maurício de Nassau. Recife, PE, Brasil.

*Study Group Members (NCOVIP) descripted at the end of the article.

\section{Abstract}

Objectives: reviewing the available literature on COVID-19 infection and the maternal and perinatal outcomes.

Methods: this is a narrative review oftheliteraturecarried out from March to September 2020, usingthe MESH: coronavirus, Covid 19, SARS-CoV-2, pregnancy, gravidity, pregnancy complications and pregnancy complications infectius. All study designs, reviews, recommendations and technical notes were included, without distinction of language and that would bring the approach ofthe new coronavirus in the gestational and perinatal scenario.

Results: the COVID-19 pandemic has had devastating effects, affecting millions of people and claiming almost a million lives worldwide. Initially, pregnant women were not seen as a risk group for the disease, however as the proportion of women affected during the pregnancy-puerperal cycle increased, several studies were published showing an increased risk of complications. Brazilian studies have also warned of a high number of maternal deaths, associated with the presence of comorbidities but, above all, with the social determinants of the disease and serious failures in care.

Conclusion: the need for new studies with an adequate research design was observed, as many studies are only letters or small series of cases, in addition expert recommendations, without the necessary scientific rigor.

Key words Coronavirus, COVID-19, Coronavirus infections, Severe acute respiratory syndrome, Coronavirus 2, SARS-CoV-2, Gestation, Maternal mortality, Perinatal mortality

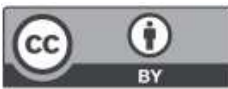




\section{Introduction}

The disease caused by new coronavirus 19 (COVID19) determined severe direct and indirect repercussions over women's reproductive health.1,2 Some indirect consequences deserve to be mentioned: interruption in women's health care; expanded demand for safe abortion services, related to the lack of contraceptives or fear of unknown consequences of COVID-19; increase in maternal death due to cases not related to COVID-19, to readjustments in health services or lack of resource allocation; 3 difficulty in restructuring of women care services to return to the pre-pandemic levels; 4 consequences of the increase in domestic and gender based violence, due to the social distancing policy and/or quarantine; 5 negative psychological effect, including posttraumatic stress disorder symptoms, confusion and anger;6 discrimination associated with COVID-19 and its effects in patients and healthcare providers; aspects related to women's mental health, once mental disorders may increase significantly. 7

In relation to direct pandemic repercussions, several doubts about specific issues persist. Although many studies have been published in the last months, scientific evidence are still scarce, particularly during pregnancy and puerperium. In face of uncertainties, we aimed to execute a literature review about the current knowledge about COVID-19 in the pregnancy-postpartum period.

\section{Physiological modifications in the pregnancy-postpartum period}

Some physiological modifications deserve highlight when the discussion comes upon pregnancy and COVID-19.1 The modifications in respiratory mechanics, rib rectification and diaphragm elevation, decreasing respiratory capacity, should be considered, being important with the evolution of pregnancy. Pregnant women even portray decreased tolerance to hypoxia, for the physiological mechanisms that make them able to provide oxygen easily to the conceptus, diminish their reserve and capability of compensate situations of stress, hypoxia and acidosis.

It is possible that hormonal and immune system alterations explain epidemiological differences of the infection by Severe Acute Respiratory Syndrome Coronavirus 2 (SARS-CoV-2) between the prepartum and postpartum periods. In pregnancy, concentrations of steroid hormones, such as estrogen and progesterone, rise increasingly and in the postpartum period, a sudden and substantial decrease in these hormone concentrations occurs. It also occurs a modulation in the immune system, assuring that the mother's organism tolerates the fetus that functions as an allotransplant. There are changes in immunological cells, including phagocytes, plasmacytoid dendritic cells (PDCs), natural killer cells (NK) and T cells in blood, mainly in the third pregnancy trimester. 8

Another aspect worth to be mentioned is related to the angiotensin-converting enzyme-2 (ACE2). It is an enzyme from the renin-angiotensin-aldosterone system, responsible to inactivate the angiotensin II, a vasoconstrictor substance related to cardiovascular diseases, converting it to angiotensin.1-7 Some studies suggested that the ACE2 receptor would be the "door knob" of the host cells for the SARS-CoV-2 entry, and the positive regulation increases susceptibility to the virus. In pregnant women, an increase in the ACE2 receptors is observed, which would augment susceptibility. 9 The relation between ACE2 and SARS-CoV-2 in pregnancy must be better studied.

\section{Epidemiology}

Epidemiological evidence prior to COVID-19 suggests that pregnant women have higher risk of severe diseases and death, as occurred in pandemics such as influenza, 1957/1958, Ebola, severe acute respiratory syndrome coronavirus (SARS-CoV), 2003, H1N1, 2009 and Middle East respiratory syndrome coronavirus (MERS-CoV), 2012.10-12 Studies show that susceptibility, morbidity and lethality in pregnant women by influenza virus are higher, lethality was $10 \%$, twice of non-pregnant women. ${ }^{11}$ Similar findings occurred with SARS$\mathrm{CoV}$ pandemic, which presented higher hospitalization in ICU, mechanical ventilation and lethality rates in pregnant women compared to non-pregnant women $(60 \%$ x $18 \% ; 40 \%$ x $13 \%$ e $30 \%$ x $0 \%$, respectively). 12

In the current pandemic, early studies did not observe the higher risk in pregnant women. ${ }^{13}$ However, further studies found higher lethality rate by COVID-19 in the pregnancy/postpartum period than in women who were not in this period. ${ }^{1}$ This high risk of infectious diseases is related to physiological alterations in respiratory, circulatory, immune and secretory systems. An American research, assuming the 2018 maternal lethality rate as a basis, projected an increase of at least 18.7 deaths per 100.000 live births as a result of COVID-19.13 We highlight that the increased risk of complications, hospitalization, hospitalization in ICUs and need for 
mechanic ventilation in pregnant women compared to non-pregnant women of the same age group was already demonstrated. 14

The COVID-19 clinical condition in pregnant women does not differ to non-pregnant. A systematic review observed that most of pregnant women were symptomatic (92.5\%). Symptoms appeared after delivery in $4.9 \%$ of women. The symptoms described were fever $(67.3 \%)$, cough $(65.7 \%)$, dyspnea $(7.3 \%)$, diarrhea $(7.3 \%)$ sore throat $(7.0 \%)$, myalgia $(6.2 \%)$, uneasiness and chills $(5.5 \%)$. Symptoms reported in less than $5 \%$ of women were nasal congestion, cutaneous rash, expectoration, headache, uneasiness and loss of apetite. 15 Pregnant women reported headache, myalgia, fever, chills and diarrhea less frequently than non-pregnant women.

A British cohort showed that more than half of admitted women with the infection were black or from another ethical minority, 70\% obese/overweight, $40 \%$ over 35 years old and one third had associated comorbidities (chronic respiratory disease, diabetes mellitus and cardiovascular disease). 16

The Center for Diseases Control and Prevention (CDC) observed that between women with COVID$19,31.5 \%$ of pregnant women needed hospitalization, however, this was necessary in $5.8 \%$ of nonpregnant women. After adjustments for age, race and presence of comorbidities, pregnant women presented significantly higher risk of hospitalization in ICUs and mechanical ventilation. There was no difference for death risk, comparing pregnant and non-pregnant women.

\section{Diagnosis in Gestation}

\section{Universal screening}

The universal screeningcan be used as a strategy in prenatal consultations or hospitalization for delivery. In prenatal care, the recommendations should follow orientations for non-pregnant patients, according to health policies of each region and country. ${ }^{13}$ However, it should be considered that the highest benefits of universal testing is in the hospitalization, once they help to determine practices of hospital isolation and bed attributions, besides orientate decisions on neonatal care and use of personal protective equipment (PPE). Clinical data offer an important opportunity to protect mothers, babies and health care teams. 13

The American College of Obstetricians and Gynecologists (ACOG) does not recommend routine tests during prenatal care or labor in asymptomatic and without positive epidemiological records. The
International Federation of Gynecology and Obstetrics (FIGO), although, recommends universal testing in the maternity hospital admission, by molecular tests Reverse-Transcriptase Polymerase Chain Reaction (RT-PCR) and not by serologic tests, which have low accuracy.

A study conducted with 215 pregnant women admitted for abortion and examined for COVID-19 symptoms, observed that only four women (1.9\%) presented fever and/or other symptoms, being tested positive for SARS-CoV-2. Of the 211 asymptomatic women, the nasopharyngeal swabs were obtained in $210(99.5 \%)$, being $29(13.7 \%)$ positive. Thus, 29 of 33 patients that tested positive $(87.8 \%)$ did not present symptoms. Of 29 asymptomatic women and who tested positive in admission, three $(10 \%)$ had fever before hospital discharge after delivery, however two of these patients received antibiotic treatment for presumed endometriosis and a patient was considered febrile due to COVID-19. A patient with negative testing in admission became symptomatic in the postpartum period, and had her test repeated, being positive. 17 Thus, it is suggested that the universal testing in pregnant women in admission for delivery in a pandemic epicenter was important, for most of patients who tested positive, at the momentof delivery, were asymptomatic. This interpretation may be limited in regions with low infection rates. 16,17

2.Radiography and Chest Computed Tomography (Chest CT)

The chest CT is essential in the assessment of clinical condition of a patient with COVID for it represents the gold standard to evaluate pulmonary impairment, with higher specificity than RT-PCR, besides the high sensibility (97\%).

Radiography and chest CT may be executed during pregnancy when prescribed, however, lung ultrasound can be a safer alternative. 18 Fetal growth restriction (FGR), microcephaly and intellectual disability are common adverse effects to the fetal exposition to high doses of radiation (>610 mGy). According to the American College of Radiology (ACR) and ACOG, the radiation dose for the fetus in chest radiography is from 0.01 to $0.66 \mathrm{mGy}$. Thus, in face of the benefit of the execution of chest CT, the latter should be used in epidemic areas. Radiography may be useful in the assessment of the evolution of the disease. The informed consent should be acquired, as well as a protection against radiation placed upon the womb.

The logistic in chest CT execution in severe patients and the need for cleaning after use in an 
infected individual should be considered, once not every services will have a specific device for these patients. Mobile radiography equipment or the execution of chest ultrasound are alternatives. ${ }^{18}$ In suspicion of pulmonary embolism, CT angiography of the chest should be preferable to the ventilation/perfusion exam, which may be highly infectious for health professionals.

\section{Lung ultrasound}

In face of the proposal of execution of ultrasound for diagnosing lung alterations that suggest COVID19 , it was suggested that during the pandemic, lung ultrasound was performed in suspect pregnant patients, concomitant to obstetric ultrasound, minimizing the risk of infection in professionals and streamlining clinical evaluation. This diagnosis methodcan be considered when radiography and chest CT are not available. However, the handling should be determined by clinical characteristics and severity of the disease, and not based on imaging. 18

In the exam, horizontal 'A lines' are present in a normal lung. When the lung loses airing, though not consolidate, it generates different forms and lengths of vertical artifacts, called 'B lines'. When the density of the peripheral lung parenchyma is magnified, the exam reveals a white area, called "white lung”, in which 'A lines' and 'B lines' are not visible, separately. Consolidation appears as a hypoechoic irregular area and pleural effusion as anechoic. 18

A guide about lung ultrasound execution in pregnant women with suspicion of COVID-19, besides the orientations on transducers and equipment cleaning was published. 18

\section{Vertical and Perinatal transmission}

\section{Vertical transmission}

There is a great discussion about vertical transmission of SARS-CoV-2. A review study described the main RNA virus infections, such as SARS-CoV, MERS-CoV, SARS-CoV-2, Human parainfluenza virus (HPIV), Human metapneumo virus (hMPV), Respiratory syncytial virus (RSV) e Influenza (including H1N1, H3N2, H5N1 and Influenza B), not being confirmed vertical transmission in any of them. In the infection by RSV and influenza, there were suspicion in one and four cases, respectively, without casual confirmation. Perinatal death was reported for SARS-CoV, MERS-CoV, SARS-CoV-2 and influenza. 19

Preliminary studies about SARS-CoV-2 were confuse, because there were uncertainties about the origin of contamination, if the newborn's RT-PCR resulted from vertical transmission or if $\operatorname{IgM}$ was produced by the newborn or by cross reaction. 20 Posterior evidence suggests that there is vertical transmission, although the frequency is low. A systematic review described a vertical transmission rate of $3.2 \%$ Nevertheless, the real frequency, risk factors, association with placental findings and real implications persist to be established. Another systematic review assessing 261 newborns with RTPCR and/or IgM for SARS-CoV-2 in the first 48 hours of life found 21 testing positive, resulting in a vertical transmission rate of $8 \%$. In one of the cases, the amniotic fluid, and in other one, placenta and fetal membrane also tested positive by RT-PCR. 21

According to the International Society of Ultrasound in Obstetrics and Gynecology (ISUOG), it is recommended that, in order to investigate the possibility of vertical transmissions, samples of blood from the umbilical cord, placental tissue, amniotic fluid and amnio-corial interface swab should be collected immediately after delivery of women with COVID-19. The newborn's pharyngeal swab and fetal and placenta tests from abortion material of women that tested positive should also be collected. Besides RT-PCR, serology test can be an important complement. The longitudinal followup of six to 18 months of the newborns of women with COVID-19 should be executed.22

\subsection{Placenta}

The analyses of placentae are essential to confirm fetal infection. However, we highlight that even finding placental laboratorial or histopathological alterations, it should be interpreted with caution. 22

The literature about possible placental alterations and their consequences is scarce. Studies about placentae of mothers with COVID-19 found evidence of bad vascular perfusion or vascular thrombosis in fetal circulation. 23,24 The importance of these findings still uncertain, although it is speculated that it might be associated with the hypercoagulability states or ischemic alterations that the disease develops, related or not to fetal and maternal immune response. 23,24 There is studies that demonstrate an inflammatory standard in some placentae, with chorioamnionitis and vileitis. 25 The association of these standards with maternal and perinatal outcomes and vertical transmission still not established, which should stimulate the execution of further studies.

We highlight that placenta should be treated as an infected tissue and handled and discarded according to safety rules. 22 Placental arts, ingestion 
of the placenta or allowing to bring it home should be avoided.

\section{Perinatal transmission}

Perinatal transmission can theoretically occur via aerosols and maternal droplets from mothers or health professionals in birth rooms or transmitted through birth canals and even through breastfeeding. However, there is no evidence of transmission by breast milk or vaginal fluids. ${ }^{26}$ Thus, most guidelines recommend breastfeeding since maternal conditions allow it and the women herself wishes it. 22

In most breast milk samples, presence of SARSCoV-2 was not verified. A study observed that a puerperal woman presented positive RT-PCR test in both breast milk and newborn. We highlight that this result does not confirm transmission via breastfeeding, 27 for the presence of viral particles can make a test positive and do not ensure infectiveness and any study in this sense should be complemented by viral culture. Breast milk is rich in antibodies and the presence of secretory IgA specific against SARS$\mathrm{CoV}-2$ was already demonstrated in mothers cured of COVID-19.

Due to SARS-CoV-2 presence in feces has been demonstrated, 28 transmission via meconium was also suggested, although without confirmation.

\section{Maternal Complications}

Studies conducted in infections caused by other coronaviruses, such as SARS-CoV and MERS-CoV found augmented risk of complications during pregnancy, such as spontaneous abortion, preterm labor (PL), premature rupture of membranes (PROM) and maternal and perinatal deaths. 29,30 Regarding COVID-19, studies also suggest adverse results, however causality is still not determined, being more described PL, PROM, FGR, low birth weight, fetal distress, abnormal fetal heart rate (FHR), cesarean section, pre eclampsia-like, HELLP-like, postpartum hemorrhage, maternal pneumonia, maternal food intolerance, fetal asphyxia and stillbirths.31,32

\section{Pneumonia}

Independently of COVID-19, pneumonia is a significant known cause of morbidity and lethality in pregnant women, being non-obstetric infection more important in this period. In $25 \%$, intensive care is necessary, with indication of mechanical ventilation being frequent and more severe when the etiological agent is viral, compared to bacterial. 33 We highlight that, independently of the etiological agent, pneu- monia in pregnancy period itself is associated with gestational complications such as PL, PROM, FGR and perinatal death.

In early studies about COVID-19 in pregnancy, it was observed mild pneumonia. This behavior differs significantly from that presented in influenza virus infection. ${ }^{34}$ However, as further studies were emerging, it was observed that COVID-19, such as other viral infections, can also cause severe pneumonia in pregnant women, with increased risk of intubation and need for mechanical ventilation. 10

\section{Premature labor (PL)}

Early studies presented high prematurity risk, generally iatrogenic and related to cesarean section. At the onset of pandemic, in face of COVID-19 in pregnancy along with SRAS, physicians, without the proper knowledge, executed cesarean section in case of intubation. As the knowledge about COVID-19 developed, the management in ICUs with transdisciplinary teams became modified and currently it is known that it is possible to let it evolve even when a pregnant woman is submitted to intubation and mechanical ventilation. Subsequent reviews reflect upon this change of behavior, estimating a prematurity rate of $23 \%$ and PL of $21 \%$.

In face of uncertainties about the risk of spontaneous prematurity, the screening of uterine lap length is not recommended in this pandemic, for it does not provide any benefits for both mother and fetus and it increases the exam time, and consequently, the exposition to health professionals. ${ }^{22}$ Nevertheless, in face of PL it is recommended that its treatment, regardless of testing positive for SARS-CoV-2 and number of fetus, be executed with tocolytic, magnesium sulfate, corticotherapy and antibiotics, when indicated.

\section{Premature detachment of normally posi-}

\section{tioned placenta (PDNPP)}

There is reports of PDNPP in pregnant women with SARS-CoV or MERS-CoV, with placental alterations, such as areas with loss of blood supply, avascular villi and retroplacental hemorrhage, although without confirmed causality. 30 In relation to COVID-19, PDNPP has not yet beeninvestigated in literature.

\section{Premature rupture of membranes (PROM)}

Genital or respiratory infections are known for being a risk factor for PROM. However, in pregnant women infected by SARS-CoV-2, although some reports are described concerning this possibility, 20 there is no studies that confirm a higher frequency of 
PROM in women with COVID-19.

\section{Abortion}

The majority of studies focus the second half of pregnancy, so that the outcomes of the first trimester, such as abortions and teratogenic effects are yet to be explored. There is little report of abortions in the first and second trimesters. 35

A Danish case series included 1,019 women tested for COVID-19 in the first trimester, with or without pregnancy loss, and submitted to screening of fetal anomalies with the double marker test (Pregnancy associated plasma protein A PAPP-A and human chorionic gonadotropin - $\beta$-hCG) and nuchal translucency. The researchers did not find difference between women who presented or not antibodies for SARS-CoV-2 in relation to abnormality frequencies in nuchal translucency, double mark test and pregnancy lost. Nevertheless, seroprevalence is low in Denmark $(1.1 \%)$, due to mobility restrictions and other implemented measures. In this way, caution is needed when extrapolating this results to the population of other countries. 36

Thus, due to the lack of evidence, it is recommended that embryos/fetuses and or placentae aborted by pregnant women with COVID-19 should be treated as infected tissues and adequately discarded. The study of material via histopathological examination and RT-PCR test for SARS-CoV-2 should be performed whenever it is possible. 22

\section{Fetal growth restriction (FGR)}

In patients infected by SARS-CoV, studies reported FGR, 29,30 given that one of them described the Doppler velocimetry of the umbilical artery as normal. 30 The association of COVID-19 with FGR still unclear.

\section{Pre-eclampsia}

A study suggested that six pregnant women with severe COVID-19 (75\%) developed a syndrome similar to pre-eclampsia. Of these, five presented alterations in uterine artery pulsatility index and angiogenic factors, and two remained pregnant after spontaneous resolution of the syndrome similar to pre-eclampsia and the severity of COVID-19.32 However, the sample was small and both angiogenic and Doppler velocimetry factors do not necessarily exclude pre-eclampsia. We agree that it is possible that some patients with COVID-19 present conditions that mimetize pre-eclampsia, however, as in our experience, patients with hypertensive syndromes are highly frequent, it is likely that this is a condition of risk of severity and lethality for
COVID-19. It is necessary to monitor what came first, pre-eclampsia and/or HELLP syndrome or COVID-19.37,38

\section{Fetal/Neonatal Complications}

There is no strong evidence that confirms vertical transmission, but it is not possible to decline that it occurs. Studies suggest that even with absent viral infection in the placenta, maternal response promotes an inflammatory fetal response, known as fetal inflammatory response syndrome (FIRS), characterized by high levels of cytokines in placenta, without cultivable microorganisms. These cytokines are not free of adverse effects, as it was observed alterations in the central nervous and circulatory systems in animal models. FIRS has been associated with autism, schizophrenia, psychoses and sensorineural deficit. 39

\section{Fetal/neonatal death}

Studies had described fetal and neonatal death in patients with COVID-19, with a stillbirth rate of $1.2 \%$ and neonatal death rate of $1.2 \% .40,41$ However, none of them can confirm a causal link. 40,41 Fetal death was described in one case, but the patient presented severe pneumonia and needed Extracorporeal membrane oxygenation (ECMO) 40 and the other had intrauterine asphyxia.

A study compared the incidence of fetal death before and during the pandemic, and observed an increase of 2.4 to 9.3 out of 1,000 , regardless of the cause. However, factors such as the lack of prenatal care and occurrence of other complications may be associated with this risk.

\section{Fetal malformation}

Most of series include pregnant women in the second half of gestation and reports of infection in the first trimester are scarce. Thus, more evidence is needed to completely withdraw the possibility of fetal malformation. We highlight the Danish study that did not find alterations in translucency or double marker test 36

\section{Pregnancy care in the COVID-19 pandemic context}

In the COVID-19 pandemic context, health professionals searched for alternatives to adapt their clinical practice to protect patients, themselves and health resources. Health systems in Brazil and other countries restricted consultations and elective procedures. However, birth cannot be considered elective. 
Thus, prenatal follow-up and labor assistance and labor cannot be restricted. 42

According to the $06 / 2020$ Technical Note from Brazilian Ministry of Health, prenatal is an essential service that should be maintained, although it should be readapted. This includes pregnant women of habitual risk having the minimum of six consultations: one at the first, two in the second and three in third semester, alternating in remote and in person consultations; restricting examinations to those that are essential,43 including unnecessary ultrasound exams.

By means of a careful and deliberated planning, changes should be defined in this attendance, aiming to reduce the exposition of infected patients to health professionals and the length of stay in clinics and hospitals, without impairing maternal and perinatal outcomes. 42 However, studies are necessary to assess the effectiveness and cost-benefit ratio of the various recommendations suggested by national and international medical societies and their governments.

\section{Screening of signs and symptoms}

The screening of pregnant women and their companions is of great relevance, and it should be executed in all attendance steps, outpatient prenatal and postpartum care and hospitalization of high-risk pregnancy, as well as labor and puerperium. 22 The number of entrances in maternity hospital should be limited, ensuring that everyone will be screened for signs and symptoms of COVID-19.42

It is essential to create a checklist of screening, allowing the identification of suspect cases, confirmed or not. When a potentially in risk patient comes, a surgical mask should be used on her, and the follow-up should preferentially made in the hospital's specific sector. Health professionals should wear adequate PPE.44

\section{Type of consultation}

It is suggested consultations by phone or videoconference, reducing infection of patients, partners/companions and health professionals. The reduction of length of stay of patients in clinics and hospital environments can be promoted, with directed consultations and execution of only essential examinations. The usage of masks by patients and frequent hand hygiene and/or 70\% alcohol should be stimulated.

In patients with negative screening, in person consultations can be executed, with the proper distancing procedures and expanded time. It is essential to maintain some in person consultations, because activities such as measuring uterine length, weight and blood pressure cannot be performed remotely and reliable devices are not always available at home.

Consultation by phone or videoconference, if appropriate, can be considered for prenatal counseling of suspect cases, confirmed or not. When not appropriate, being necessary in person attendance, an isolation area should be provided, whether in outpatient clinics or hospitals. Patients should wear masks, avoid bringing companions and PPE is mandatory. 44

\section{Medical care location}

Suspect and probable cases in pregnancy should be submitted to screening. Suspect, probable and confirmed cases considered mild and without risk factors can be handled in primary healthcare, orientating to lockdown and domiciliary treatment linked to basic health units. Whilst moderate/severe cases should be forwarded precociously to tertiary hospitals. It is recommended isolation rooms with negative pressure, although this resource is rarely found in our environment. 45

Preferentially, maternity hospitals or natural childbirth centers should be selected to exclusive treatment of suspect, probable and confirmed cases. These locations should build specific environments for vaginal delivery and surgeries, neonatal isolation in ICUs or intermediate care and shared accommodation. 22

\section{Attendance room and isolation}

In suspect, probable or confirmed cases that need in-person, outpatient or hospital attendance, it is recommended that they be placed in isolation. In this isolation rooms, the circulation of patients and health professionals should be limited to the sector. 46

If the screening sector of the maternity is contacted before the pregnant women arrives, the managers of the sector should organize and prepare resources. Ideally, in patients with confirmed COVID-19, negative pressure room would be necessary. If unavailable, it is recommended an exclusive room with all unnecessary equipment withdrawn.

Disinfection of the room and used equipment should be performed according local protocols. 44 Equipment should be exclusive, such as electronic fetal monitor (EFM) or ultrasound devices, and they should not be displaced and disinfection between patients must be done.

Immediate review of the exams performed by the team's senior members, and, if necessary, by multidisciplinary team is recommended, avoiding further 
unnecessary contact, and decreasing the time of hospitalization. Although they are in isolation nurseries, not only specialized care but also psychosocial support, as well as the multidisciplinary team, still important. 47

\section{Main Obstetric Procedures}

\section{Elective non-pharmacological labor induc-} tion

Deve-se pensar em adiar as induções eletivas com pontuação ruim do escore de Bishop. Embora a taxa de cesariana não aumentou com a indução acima da $39^{\text {a }}$ semana de gravidez, outro estudo estabeleceu que o tempo para o parto e de internação aumentaram. 48 Pois, uma indução do trabalho de parto, mesmo com parto vaginal bem sucedido, aumenta o tempo de exposição para pacientes, parceiros/acompanhantes e profissionais da saúde. No entanto, induções obstetricamente indicadas não devem ser adiadas. 22

\section{Conservative procedure in PROM}

The benefits of the additional time in utero for the fetus in PROM up to 34 weeks were demonstrated, 49 however, in face of COVID-19, considerations will be discussed. ${ }^{22}$

In spite of the study, executed between 34 and 36 6/7 weeks in pregnant women with PROM, did not demonstrate increased risk of sepsis or neonatal morbidity, in pandemics, due to additional risks associated with expanded hospital stay, the gestational age for interruption of pregnancy should be determined.50 Maternal morbidities, such as hemorrhage and infections were more frequent with expectant treatment after 34 weeks, expanding even more the hospital stay. 50 Thus, in face of little perinatal benefits and additional increase of maternal complications, it is recommended that the conservative procedure be executed up to the $34^{\text {th }}$ week of pregnancy. 22

Another study was carried out comparing pregnant women with PROM submitted to active procedure after the 32th week, by labor induction, to the expectant treatment up to 34 weeks, not evidencing any difference in the neonatal results. This study can corroborate the indication of pregnancy interruption, after the $32^{\text {th }}$ week, in more severe situations. 49

\section{Antenatal Corticotherapy}

Corticoids are indicated between 24-34 weeks in pregnancies with prematurity risk, which does not change in pandemic context. However, there is a concern with the use between 34-36 weeks and repe- tition of doses.

The ACOG recommends that in a gestational age inferior to the $34^{\text {th }}$ week, current practices should be followed. However, the use after 34 weeks or performing rescue doses should be reconsidered during COVID-19, particularly, because the benefits 51,52 remain unclear. ${ }^{22}$ In this way, due to inconsistences and the possibility of suppression of the maternal immune response associated with corticosteroids, it is recommended that their regular use in late preterm and the rescue dose be discouraged during pandemic. 22,53

For suspect, probable or confirmed cases of COVID-19 with gestational age inferior to 34 weeks, it is recommended to evaluate risks and benefits. It is recommended to use corticoids in case of risk of prematurity, being preferable betamethasone in order to not confuse with dexamethasone, which is used in severe cases for specific COVID-19 treatment.

In patients with stable conditions, such as eclampsia, pulmonary edema, acute respiratory distress syndrome, barotrauma, disseminated intravascular coagulation, PDNPP and abnormal FHR, corticoid should be administered after maternal stabilization, but it will be not always possible to wait for the effect. 22

\section{Tocolysis}

The discussion about risk-benefit must also be applied to tocolysis usage, 22 with no contraindication of its use in suspect, probable or confirmed cases.

\section{Magnesium Sulfate}

It is recommended the use of magnesium sulfate for fetal neuroprotection in pregnant women with gestational age inferior to $32^{\text {th }}$ week and treatment/convulsion prophylaxis in pre-eclampsia/ eclampsia, with the usual dose, including during pandemic.22,54 The administration should be carried out with caution when the patient presents dyspnea.

\section{Doppler velocimetry and ultrasound moni-} toring

When COVID-19 is acquired in the first or second pregnancy trimester, it is indicated morphology ultrasound between 10 and 14 weeks and 18 and 24 weeks, and they should be monitored after recovering. Pregnancy should be managed according to clinical findings, independently of the moment of infection. Clinical visitations to obstetric emergency rooms will be carried out according to local guidelines. In case of positive screening, routine consultations should be postponed for 14 
days after the onset of symptoms or 2 negative tests. 22

Pregnant women with confirmed infection, asymptomatic or recovering from a mild illness, should be monitored with biweekly ultrasounds, for evaluation of fetal growth and amniotic fluid, besides Doppler velocimetry of the umbilical artery, if necessary. 55 In severe cases, the exams can be performed when the patient is stabilized. The exams should be carried out respecting disinfection and safety rules and using PPE.

\section{Strategies of ventilation in pregnancy}

Initially, based on Chinese study findings, early intubation was indicated for all patients with dyspnea. However, this strategy lead to long periods of intubation and ventilation and difficulties in weaning, observing a different standard than that found in patients with Acute respiratory distress syndrome (ARDS). Gradually, new invasive and non-invasive ventilation strategies were used with a relative success. This includes the possibility of prone positioning with spontaneous ventilation, usage of non-humidified $\mathrm{O}_{2}$ catheter with $4 \mathrm{~L} / \mathrm{min}$ at maximum, Venturi mask, mask with reservoir bag and non-invasive ventilation. 56

In pregnant women, special beds can be adopted for prone positioning or, alternatively, try lateral decubitus position, enrolling the affected areas. We highlight that the limit for non-invasive ventilation in pregnant women is lower due to physiological pregnancy characteristics, including higher oxygen consumption, for levels of partial $\mathrm{O}_{2}$ pressure, $\left(\mathrm{PaO}_{2}\right)$ which would be well tolerated by non-pregnant women, can be critical for pregnant women. Although non-invasive alternatives should be attempted, early intubation when it is not possible to obtain $\mathrm{PaO}_{2}$ around $90 \mathrm{mmHg}$ should be considered. The $\mathrm{O}_{2}$ saturation $\left(\mathrm{SatO}_{2}\right)$ will not orientate this decision, but gasometry parameters.

\section{Child Birth Planning}

1. Child birth environment designed for suspect, probable and confirmed cases

Ideally, birth rooms and surgery rooms for obstetric and neonatal care to pregnant women with COVID-19 should be equipped with high efficiency filtration system and negative pressure. This equipment are not available in public services and most of private services in Brazil. The rooms must be exclusive, broad, isolated and distant from other rooms. After use, disinfection should be performed.22 The usage of labor, delivery and recovery rooms (LDR) is an alternative.

Shared accommodation can be used in mild/moderate cases, ensuring a physical barrier of $2 \mathrm{~m}$ with a curtain or screen, between mother and baby, except during breastfeeding.

\section{Limiting visitors}

There must be restrictions to visitations. It is recommended to adopt a universal policy of nonvisitation, for people should keep physical distancing and stay at home. Only one companion should be allowed, of the woman's familiarity, and he/her should be asymptomatic and out of risk groups, avoiding rotating companions. The technical note from the Ministry of Health 09/2020 assure the right of one companion in labor and delivery, although it suggests that the companion must leave within two hours after delivery. However, the Public Ministries of many locations, considering national Law 11.108/2005, emitted recommendations to ensure the presence of one companion during the entire labor, delivery and postpartum, using mask at full time.

It is recommended adherence to local protocols, considering overcrowding and consequent agglomeration of patients, companion/partners and health professionals. Parturients and companions should receive masks and perform hand hygiene frequently. 22

\section{Personal protective equipment (PPE) in} suspect, probable and confirmed cases

Respiratory cautions should be used in all labor areas by patients, partners/companions and health professionals. The use of surgical masks should be encouraged full time, as well as frequent hand hygiene, mainly for suspect, probable and confirmed patients.

Deliveries should be assisted with complete vestments, medical caps, surgical mask, face shield, impermeable apron and gloves, however, ins suspect, probable and confirmed cases we add that masks should be of the N95/PFF2 type. $22,52,57$ N95 masks should be mandatorily used whenever procedures that generate aerosols are being performed, mainly in the expulsive period, as well as in cesarean sections and postpartum hemorrhage that needs transferal to intubation or surgical room. 57

PPE usage for vaginal delivery or cesarean requires time. Thus, health professionals should anticipate themselves, having adequate time, and clarifying both parturient and companion about this delay. 22

The PPE should be used according the assistance 
level (Table 1).58-60

\section{Transferals}

In order to transfer suspect, probable or confirmed cases, the medical team should use PPE and keep minimum distance of $2 \mathrm{~m}$ to individuals without PPE. 22

\section{Procedure during Labor}

\section{Type of delivery}

The type of delivery should be individualized based on obstetric indications, favoring vaginal delivery in order to avoid surgical complications.22,56,61 Since there is indication and execution at the proper gestational age, elective cesarean section should not be postponed or anticipated. The postpartum hospital discharge should follow the same standard used prior to pandemic.

The obstetric and neonatal outcomes in pregnant women with COVID-19 are unclear and it is unknown whether vaginal delivery increases perinatal transmission risk. Otherwise, it is important to highlight that reported cases that suggested vertical transmission were from cesarean section newborns. 21,62

Regarding the fact of the suspect, probable or confirmed pregnant women needs treatment due to complications from the disease, it might be necessary to postpone cesarean section to optimize respiratory status. 61,63

The decision about delivery in pregnant women with severe COVID-19 infection is challenging. It is recommended that this decision considers gestational age, associated diseases and fetal/maternal status. 61 There is no consensus for anticipating delivery and for compromised fetal vitality be the main factor for delivery anticipation. Authors suggest that, in situations such as uterine secondary distention, multifetal gestations, macrosomia and polyhydramnios, among others, that can result in impairment of cardiopulmonary function due to diaphragm displacement, anticipation of delivery should be discussed. In these patients, mainly when endotracheal intubation is required, delivery at $32^{\text {th }}$ week should be considered, judging risks and benefits and conditions at the NICU.

\section{Delivery positioning}

Most positions are recommended, with preference to vertical positioning. Delivery in water should be avoided, due to the presence of virus in feces, with high potential of infection.

\section{Anesthesia}

Local and general anesthesia can be considered, depending on the clinical conditions. Once general anesthesia is an aerosol generating procedure, local anesthesia is preferred. When appropriate, early peridural anesthesia for vaginal delivery should be considered.

4. Limiting frequency and duration of room entrances and number of cervical exams

Frequency and time in prepartum and delivery rooms should be limited, as well as the number of cervical exams, by nurses and physicians. Actually, 2018 guidelines from WHO preconize to restrict these exams, performing them every four hours or only if necessary.

5. Monitoring maternal clinical conditions vital signs and SatO

The patient with COVID-19 can hardly tolerate labor and become highly fatigued. In cases of fatigue and decrease of $\mathrm{SatO}_{2}$ before the dilatation is complete and when vaginal delivery is not anticipated for soon, the indication is cesarean section.

\section{Accelerating the second phase of labor}

In the specific case of pregnant women with COVID-19, to monitor $\mathrm{SatO}_{2}$ and maternal and fetal wellbeing, for indication to abbreviate the second stage due to $\mathrm{SatO}_{2}$ decrease, maternal fatigue or abnormal FHR can occur.

\section{Fluids and oxytocin}

The administration of fluids is controversial, once instable patients with COVID-19 can be congested and overloaded with fluids and aggressive hydration leads to worsening, altering the oxygenation of maternal tissues and causing hemodynamic decompensation. It is recommended to use 250-500 $\mathrm{ml}$ bolus, evaluating before advancing. 51 However, hydric and nutritional support should be ensured to pregnant women, as well as the balance of water and electrolytes, monitoring vital signs and $\mathrm{SatO}_{2}$.

Regarding oxytocin usage, caution with the physiological solution of sodium chloride $(\mathrm{NaCl})$ is needed, due to the potential increase of volume overload compared to other solutions, which can predispose to pulmonary congestion due to the sodium. Thus, if intravenous fluids are necessary for pregnant women whose labor is not predicted, fluids with reduced sodium concentration $(1 / 2$ to $1 / 4$ of the $\mathrm{NaCl}$ solution of $0.9 \%$ ) are preferred, because in case of the delivery is anticipated due to cesarean section 


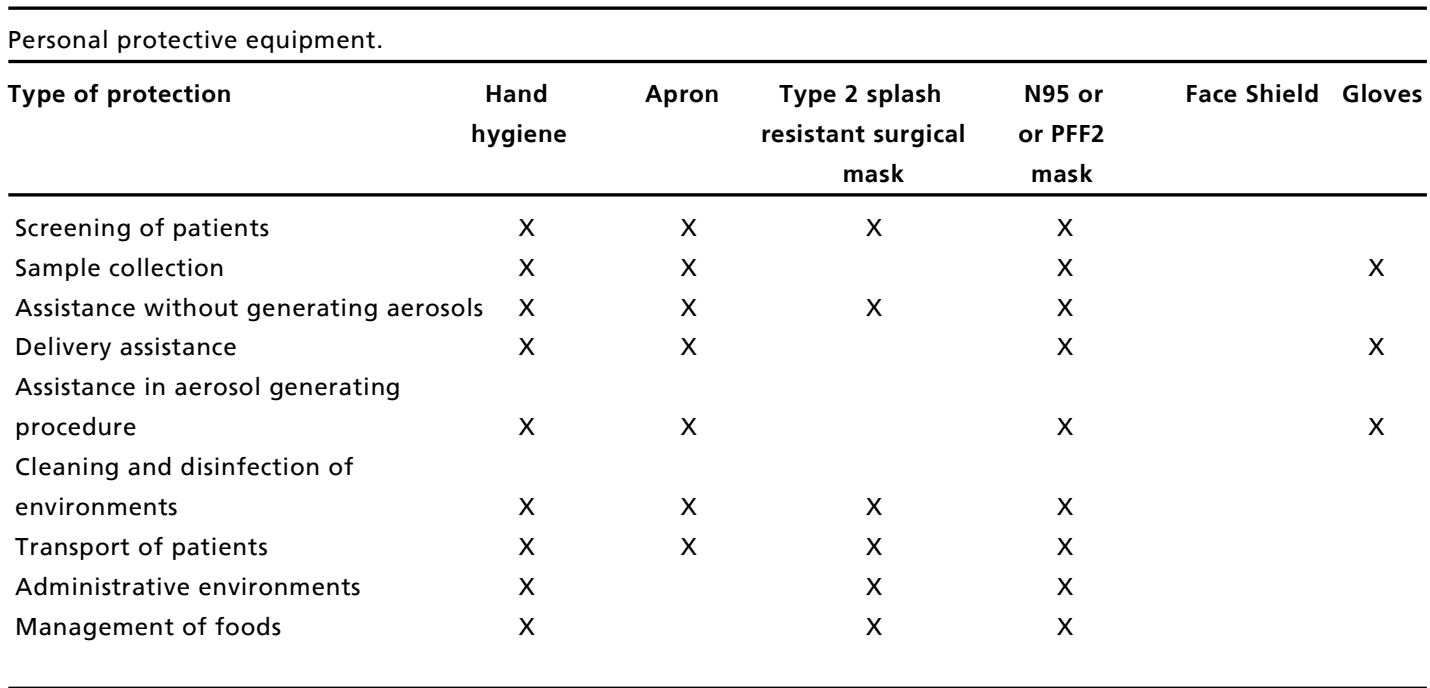

Source: Health Institute Elpídio de Almeida (ISEA - Portuguese acronym), 202058; Brazilian Intensivist Medicine Association (AMIB - Portuguese acronym), 202059 ;Center for EvidenceBased Medicine (CEBM), 2020.60

indication, there is a risk of pulmonary congestion.

\section{Pullsat the second stage of labor}

Pregnant women with SARS-CoV-2 are under risk, mostly at labor, where the effort can lead to distress or acute respiratory failure. In this way, abbreviating the second active phase of labor should be considered, which also decreases the exposition to the health professionals team and the companion.

Deep breathing and expulsive maternal efforts may increase the exposition of the partner/ companion and health professionals to respiratory fluids, and it should be discouraged at any phase of labor. We highlight that the patient should not be discouraged to pull at the moment of contraction, if she wants it. Valsava maneuver is not recommended. Mask usage by the parturient during the entire labor process is recommended, however some patients may not tolerate it well, especially in the expulsive period, and the Brazilian Ministry of Health suggests that the mask can be removed in this moment.

In relation to pregnant women without diagnosis, but who can be asymptomatic, the recommendations are the same. 22

\section{Maternal Oxygen therapy}

Maternal oxygen supply has been used intrapartum in face of abnormal FHR. Although, evidence does not suggest benefits.64 Studies suggested risks to the neonate, including prolonged resuscitation and acidemia, in which the supplementarylow flow nasal oxygen $(2 \mathrm{~L} / \mathrm{min})$ does not affect the $\mathrm{pH}$ of the umbilical artery. 64 In this way, the use of maternal oxygen therapy for maternal hypoxia, and not for fetal resurrection.

In face of these uncertainties, oxygen supply in case of fetal hypoxia and abnormal FHR is being discouraged due to supplementation sometimes occur via facial masks, which generate aerosols.

Health professionals should be aware of the WHO recommendations that preconize caution in air transmission in healthcare, including isolation rooms and use of masks, and in the risk during non-invasive ventilation and oxygen therapy.

\section{Procedure at Birth}

\section{Opportune clamping of the umbilical cord}

For women with confirmed or suspect COVID19, although Chinese and FIGO guidelines recommend early clamping of the umbilical cord, there is no evidence of benefits in preventing vertical transmission, being undeniable the beneficial effects of late clamping, which should be chosen by opportune clamping. The collect for cord blood banks may be performed, for the risk of transmission of SARS$\mathrm{CoV}-2$ by blood products is uncertain. 65

\section{Neonatal care}

Newborns of mothers with COVID-19 are considered suspect cases and should be tested, isolated, treated and the cautions of infection control should be performed. Newborns should be tested as soon as possible, mainly in the first 24 hours of age 
and repeat within 48 hours, with throat and nasopharyngeal swab samples, and rectal samples, if available. 65

Congenital infection with fetal death is confirmed if the virus is detected by RT-PCR in fetal or placental tissue, or electronic microscopy or viral culture in placental or fetal tissue. The detection of the virus by RT-PCR in fetal tissue or tissue from the fetal side of placenta would be classified as possible infection, being unlikely if the virus was detected only in the maternal side of placenta. The absence of infection would be based in the non-detection of the virus by RT-PCR or electronic microscopy in autopsy of fetal tissues. 65

Congenital infection in newborns of mothers with COVID-19 depends on clinical characteristics. In symptomatic newborns, it is confirmed when detected by RT-PCR in the umbilical cord blood or neonate's blood in 12 hours of life or the amniotic fluid collected before the rupture of membranes. In asymptomatic newborns, it is confirmed if detected by RT-PCR in the umbilical cord blood or neonate blood in 12 hours after delivery. 65

Neonatal infection can be acquired intrapartum, being confirmed in symptomatic newborns from infected women, if RT-PCR is positive at $24 \mathrm{~h}$ to $48 \mathrm{~h}$ of age (after cleaning) and unexplained symptons. 65 Asymptomatic newborns from infected women are confirmed when RT-PCR is positive at $24 \mathrm{~h}$ to $48 \mathrm{~h}$ of age (after cleaning). 65

Neonatal infection can be acquired after delivery, being defined by clinical characteristics after 48 hours of age (regardless of parents/caregiver are positive) and negative RT-PCR at birth, but positive after 24 hours of life via nasopharyngeal/rectal swab. 65

\section{Early skin-to-skin contact}

The recommendations on early skin-to-skin contact are controversial, however, with some modifications, the contact should be ensured and stimulated. A group suggested to let the vernix for 24 hours after birth, once it contains antimicrobial peptide, whilst others advice to bath as soon as possible to remove the virus present on skin.

WHO defends early skin-to-skin contact of the newborn and his genitor, even in puerperal women with COVID-19. However, it should be assured the use of masks and frequent hand hygiene. 51 It is recommended that this contact should be performed after maternal hand hygiene, changing bed sheets, nightdresses and masks, which can be performed while waiting for umbilical cord clamping.

The separation between mother with COVID-19 and newborns was initially proposed by Chinese physicians and the CDC, when the disease was little known, and the decision should be shared by both mother and medical team. ${ }^{65}$ However, many global guidelines, including $\mathrm{WHO}$, proceed in an opposite direction.

\section{Breastfeeding}

Relieving information suggests absence of transmission via breast milk, although evidence are inconclusive. 4 In face of benefits of breastfeeding, the main national and international institutions opt to ensure breastfeeding for suspect, probable or confirmed patients. 5,6,22,51 Breastfeeding the child can also provide passive protection of antibodies against SARS-CoV-2. Apparently, there is no transmission via breast milk, but there is concerning about the risk of infection, once an infected mother may transmit by intimate contact. The use of masks, respiratory etiquette and frequent hand hygiene should be stimulated.22,57

For a pregnant woman in severe or critical conditions, separation of mother and baby seems to be the best option, with the recommendation of milking breast milk for sustaining milk production, with breastfeeding pump hygiene and a healthy caregiver, following hygiene caution procedures. When the newborn is hospitalized in NICU and the mother is in a good condition, milking and offering milk to the baby is recommended, with hand hygiene and facial mask while milking.

\section{COVID-19 treatment in pregnant/ puerperal women}

\section{Use of Nonsteroidal anti-inflammatory} drugs (NSAIDs)

In pregnant women, NSAIDs should be avoided for they lead to repercussions in the fetus, being allowed in puerperium. Due to the lack of conclusive data, it is recommended to use them when indicated.

\section{Thromboprophylaxis}

It is recommended to use a prophylactic dose of a low molecular weight heparin (enoxaparin) for pregnant women with COVID-19, maintaining it after hospital discharge, in pregnant or puerperal women normal postpartum, for seven days, or after cesarean section, for 14 days. For asymptomatic patients, assess necessity in case of risk factors. Safety analysis should be performed regarding the concomitant use with neuraxial analgesia.

Generally, the prophylactic recommended dose for enoxaparin is $40 \mathrm{mg}$, subcutaneous, and it can be 
adjusted according to bodyweight (Table 2). 58

Enoxaparin in full dose should be administered in patients with thromboembolic events, or with Ddimer elevation above $3,000 \mathrm{ng} / \mathrm{dL}$, in a dose of $1 \mathrm{mg} / \mathrm{kg}$ every 12 hours, which should be corrected in cases of renal insufficiency. Non-fractionated heparin can be an alternative in the 10,000 UI dose every eight hours. We highlight the importance of being aware to pulmonary embolism diagnosis.

\section{Referral to intensive care unit}

It is extremely important to monitor pregnant and puerperal women with COVID-19, allowing the fast onset of intensive care. Although it is not yet validated for pregnant women with COVID-19, the Modified Early Obstetric Warning System (MEOWS) can be used to early recognition of critical diseases (Table 3).9,66

Due to absence of validated criteria, the Integrative Medicine Institute Prof. Fernando Figueira (IMIP - Portuguese acronym) and Health Institute Elpídio de Almeida (ISEA - Portuguese acronym) proposed new criteria for hospitalization in ICUs (Table 4). 58

\section{Final Considerations}

Some evidence needs to be highlighted, such as the importance of preventive measures, higher rates of lethality and complications in pregnant and puerperal women, the possibility of vertical transmission, the absence of an effective treatment, mainly for pregnant women, the urgent need for an effective vaccine. These are some suggested evidence, although the high number of national and international publications. However, uncertainties about COVID-19 in pregnancy/puerperal period persist, being necessary well designed studies with sufficient sample size, for the majority of studies found, mainly at the onset of pandemic, were reports or case series and observational studies with small sample size.

\section{Author's collaboration}

Research's conception and design:Amorim MMR, Souza ASR, Melo ASO, Katz L; Achievement of articles: Amorim MMR, Souza ASR, Melo ASO, Delgado AM, Florêncio ACMCC, Oliveira TV, Lira LCS, Sales LMS, Souza GA, Melo BCP, Morais I, Katz L; Evaluation and interpretation of articles and writing of the manuscript:Amorim MMR, Souza ASR, Melo ASO, Delgado AM, Florêncio ACMCC, Oliveira TV, Katz L; Manuscript review: Amorim MMR, Souza ASR, Melo ASO, Delgado AM, Florêncio ACMCC, Oliveira TV, Lira LCS, Sales LMS, Souza GA, Melo BCP, Morais I, Katz L, NCOVIP; Critical review: Amorim MMR, Souza ASR. All authors approved the final version of the article.

\section{*Members of the NCOVIP Group}

Beatriz dos Santos Moura, Chistiane Tiné Cantilino, George Augusto da Fonseca Carvalho Antunes de Lima, Glaucia Virginia de Queiroz Lins Guerra, Irla Valença Araujo, Isabela Coutinho, José Roberto da Silva Júnior, Judith Corrêa Rego, Liana Lira, Luiza Rocha de Souza, Maria Clara Coutinho, Maria Luiza Câmara, Mayara Biase, Mayara Telino, Nathália Mello, Pedro Igor Alves de Barros Lins, Antônio Fragoso, Gustavo Fonseca de Albuquerque Souza, Lucas Machado Farias, Manoel Luiz Ferreira Junior, Maria Zilda Lacerda, Raissa Lemos, Sara Katz, Eduarda Coutinho Albuquerque Neiva Coêlho, Adara Cabral Resende, Antônio Henriques de França Neto, Arthur Ferreira Cerqueira Amorim, Beatriz Bezerra de Oliveira, Bianca Conserva Freire, Clara de Araújo Dantas Teixeira, Ester Soares de Almeida, Fabiana de Oliveira Melo, Fernanda Joyce Muniz Macedo, Gabrielle Avelino Diniz Gonzaga, Girlene Souza de Azevedo, Ionara Neves Bezerra, Janine Florêncio de Souza, Lucas Felix Marinho Neves, Luccas de Oliveira Madruga, Maria Eduarda Gurgel Medeiros, Marina Amorim Albuquerque, Paula de

Table 2

\begin{tabular}{lc}
\hline \multicolumn{2}{l}{ Prophylactic enoxaparin dose according to patient's bodyweight. } \\
\hline Body weight & Recommended dose -subcutaneous \\
\hline$<90 \mathrm{~kg}$ & $40 \mathrm{mg} / \mathrm{day}$ \\
$91 \mathrm{~kg}-130 \mathrm{~kg}$ & $60 \mathrm{mg} / \mathrm{day}$ \\
$131 \mathrm{~kg}-170 \mathrm{~kg}$ & $80 \mathrm{mg} / \mathrm{day}$ \\
$>170 \mathrm{~kg}$ & $0.6 \mathrm{mg} / \mathrm{kg} / \mathrm{day}$
\end{tabular}

Source: Health Institute Elpídio de Almeida (ISEA - Portuguese acronym), 2020.58 
Table 3

Modified Early Obstetric Warning Score (MEOWS)

Limit to intervention

\begin{tabular}{lll}
\hline 1 mild & 2 mild or 1 severe & $>2$ mild and 1 severe \\
\hline $\begin{array}{l}\text { Repeat observation of all vital } \\
\text { signs between } 30 \text { to } 60 \text { minutes }\end{array}$ & Call obstetrician to evaluate & $\begin{array}{l}\text { Call obstetrician and } \\
\text { immediate review }\end{array}$ \\
& $\begin{array}{l}\text { Repeat observation of vital signs } \\
\text { after } 30 \text { minutes }\end{array}$ & $\begin{array}{l}\text { Repeat observation of vital signs in } 15 \\
\text { minutes or monitor continuously }\end{array}$
\end{tabular}

Analytical alterations and severity risk factors associated with a worse clinical evolution

\begin{tabular}{|c|c|c|c|}
\hline Vital Signs & Normal & Mild & Severe \\
\hline Respiratory rate & $11-19 / \min$ & $20-24 / \mathrm{min}$ & $\begin{array}{l}<\text { or }=10 / \mathrm{min} \\
>\text { or }=25 / \mathrm{min}\end{array}$ \\
\hline Oxygen Saturation & $96-100 \%$ & - & $<o r=95 \%$ \\
\hline Temperature $\left({ }^{\circ} \mathrm{C}\right)$ & $36.0-37.4$ & $\begin{array}{l}35.1-35.9 \\
37.5-37.9\end{array}$ & $\begin{array}{l}<0 r=35 \\
>o r=38\end{array}$ \\
\hline Heart rate & $60-99 / \mathrm{min}$ & $\begin{array}{c}50-59 / \mathrm{min} \\
100-119 / \mathrm{min}\end{array}$ & $\begin{array}{l}<\text { or }=49 / \mathrm{min} \\
>\text { or }=120 / \mathrm{min}\end{array}$ \\
\hline Systolic blood pressure & $\begin{array}{l}100-139 \mathrm{mmHg} \\
140-159 \mathrm{mmHg}\end{array}$ & $90-99 \mathrm{mmHg}$ & $\begin{array}{c}<\text { or }=89 \mathrm{mmHg} \\
>\text { or }=160 \mathrm{mmHg}\end{array}$ \\
\hline Respiratory rate & $11-19 / \mathrm{min}$ & $20-24 / \mathrm{min}$ & $\begin{array}{l}<\text { or }=10 / \mathrm{min} \\
>\text { or }=25 / \mathrm{min}\end{array}$ \\
\hline Oxygen Saturation & $96-100 \%$ & -- & $<o r=95 \%$ \\
\hline Temperature $\left({ }^{\circ} \mathrm{C}\right)$ & $\begin{array}{l}36.0-37.4 \\
37.5-37.9\end{array}$ & $35.1-35.9$ & $\begin{array}{l}<o r=35 \\
>o r=38\end{array}$ \\
\hline Heart rate & $\begin{array}{c}60-99 / \mathrm{min} \\
100-119 / \mathrm{min}\end{array}$ & $50-59 / \mathrm{min}$ & $\begin{array}{l}<\text { or }=49 / \mathrm{min} \\
>\text { or }=120 / \mathrm{min}\end{array}$ \\
\hline Systolic blood pressure & $\begin{array}{l}100-139 \mathrm{mmHg} \\
140-159 \mathrm{mmHg}\end{array}$ & $90-99 \mathrm{mmHg}$ & $\begin{array}{c}<o r=89 \mathrm{mmHg} \\
>\text { or }=160 \mathrm{mmHg}\end{array}$ \\
\hline Diastolic blood pressure & $50-89 \mathrm{mmHg}$ & $\begin{array}{l}40-49 \mathrm{mmHg} \\
90-99 \mathrm{mmHg}\end{array}$ & $\begin{array}{c}<o r=39 \mathrm{mmHg} \\
>o r=100 \mathrm{mmHg}\end{array}$ \\
\hline Neurological response & Alert & - & $\begin{array}{l}\text { Sound response } \\
\text { Painful response } \\
\text { Non-responsive }\end{array}$ \\
\hline
\end{tabular}

Source: Adapted Irish Maternity Early Warning System (IMEWS), 2019.66 
Criteria for hospitalization in Intensive Care Unit (ICU).

\section{Criteria for hospitalization in ICU}

- Necessity of $\mathrm{O}_{2}$ supply higher than $4 \mathrm{~L} / \mathrm{min}$ to maintain saturation above $94 \%$ and/or

- $\mathrm{RR}>25$ rim even with oxygen supply. and/or

- Necessity of mechanical ventilation. and/or

- Signs of organic dysfunction.

and/or

- Increase of SOFA in 2 points or more in relation to baseline.

and/or

$\mathrm{L} / \mathrm{min}=$ litres per minute; $\mathrm{RR}=$ respiratory rate; SOFA- severity score=>Sequential Organ Failure Assessment. Source: Health Institute Elpídio de Almeida (ISEA - Portuguese acronym), 2020.58

Carvalho Martins Fonseca, Thales Albuquerque Rocha, Raphaela Nóbrega Ramos, Suélem Tais Clementino Ribeiro de Menezes, Isabella Abrantes Leite Batista, Laísa Morgana Sales Brito, Lidie Anne Diniz Viégas, Maria Clara Nascimento Lopes, Roberto Magliano de Morais, Viviane Meneghetti Ugulino Azevedo Isidro, Áfia Regina da Silva Gouveia, Débora Melo Sarmento Rodrigues, Kárita Morrana de Lima Nunes, Renata de Moura Teixeira, Tatiana Viana Fragoso Vieira, Amanda Apolori Tissiani, Germana Lucena de Andrade, Marcelo Paulo Tissiani, Roberto Magliano de Morais Filho,

\section{References}

1. Tan W, Zhao X, Ma X, et al. A Novel Coronavirus Genome Identified in a Cluster of Pneumonia Cases - Wuhan, China 2019-2020. China CDC Wkly. 2020;2:61-62.

2. Fan C, Li K, Ding Y, Lu WL, Wang J. ACE2 Expression in Kidney and Testis May Cause Kidney and Testis Damage After 2019-nCoV Infection. medRxiv. Published online February 2020:2020.02.12.20022418.

3. Roberton T, Carter ED, Chou VB, et al. Early estimates of the indirect effects of the COVID-19 pandemic on maternal and child mortality in low-income and middle-income countries: a modelling study. Lancet Glob Heal. 2020;8:e901-e908

4. Delamou A, Ayadi AM El, Sidibe S, et al. Effect of Ebola virus disease on maternal and child health services in Guinea: a retrospective observational cohort study. Lancet Glob Heal. 2017;5(4):e448-e457.

5. Chynoweth SK, Amsalu R, Casey SE, McGinn T. Implementing sexual and reproductive health care in humanitarian crises. Lancet. 2018;391(10132):1770-1771.
Ana Caroline Paraguay Martins, Maria Luiza Cordeiro Nóbrega Carvalho, Pedro Henrique Carneiro da Cunha Florêncio, Victor de Medeiros Cabral, Marcelo Marques de Souza Lima, Maria Clara Silva Ferreira, Samira Rios da Silva, Shirlley Karolinny Alves Alberico, Francisco Edson de Lucena Feitosa, Carolina Dornellas Costa Lima, Jordana Parente Paiva and Priscila Fiusa Lyra Miná.

6. Brooks SK, Webster RK, Smith LE, et al. The psychological impact of quarantine and how to reduce it: rapid review of the evidence. Lancet. 2020;395(10227):912-920.

7. Souza ASR, Souza GFA, Praciano GAF. A saúde mental das mulheres em tempos da COVID-19. Rev. Bras. Saude Mater. Infant. 2020;20(3):659-661.

8. Kraus TA, Engel SM, Sperling RS, et al. Characterizing the pregnancy immune phenotype: Results of the viral immunity and pregnancy (VIP) study. J Clin Immunol. 2012;32(2):300-311.

9. Joyner J, Neves LAA, Granger JP, et al. Temporal-spatial expression of ANG-(1-7) and angiotensin-converting enzyme 2 in the kidney of normal and hypertensive pregnant rats. Am J Physiol Integr Comp Physiol. 2007;293(1):R169-R177.

10. Price ME, Fisher-Hoch SP, Craven RB, McCormick JB. A prospective study of maternal and fetal outcome in acute Lassa fever infection during pregnancy. BMJ. 1988;297(6648):584-587. 
11. Eickhoff TC. Observations on Excess Mortality Associated with Epidemic Influenza. JAMA. 1961;176(9):776.

12. Chui ML, Shell FW, Tse NL, et al. A case-controlled study comparing clinical course and outcomes of pregnant and non-pregnant women with severe acute respiratory syndrome. BJOG An Int J Obstet Gynaecol. 2004;111:771774

13. Wu C, Yang W, Wu X, et al. Clinical Manifestation and Laboratory Characteristics of SARS-CoV-2 Infection in Pregnant Women. Virol Sin. 2020;35(3):305-310.

14. Kayem G, Lecarpentier E, Deruelle P, et al. A snapshot of the Covid-19 pandemic among pregnant women in France. Journal of Gynecology Obstetrics and Human Reproduction. 2020:101826.

15. Elshafeey F, Magdi R, Hindi N, et al. A systematic scoping review of COVID-19 during pregnancy and childbirth. Int J Gynaecol Obstet. 2020;150:47-52.

16. Knight M, Bunch K, Vousden N, et al. Characteristics and outcomes of pregnant women admitted to hospital with confirmed SARS-CoV-2 infection in UK: national population based cohort study. BMJ. 2020;369:m2107.

17. Sutton D, Fuchs K, D'Alton M, Goffman D. Universa Screening for SARS-CoV-2 in Women Admitted for Delivery. N Engl J Med. 2020;382(22):2163-2164.

18. Moro F, Buonsenso D, Moruzzi MC, et al. How to perform lung ultrasound in pregnant women with suspected COVID-19. Ultrasound Obstet Gynecol. 2020;55(5):593598.

19. Schwartz DA, Dhaliwal A. Infections in Pregnancy With COVID-19 and Other Respiratory RNA Virus Diseases Are Rarely, If Ever, Transmitted to the Fetus: Experiences With Coronaviruses, Parainfluenza, Metapneumovirus Respiratory Syncytial Virus, and Influenza. Arch Pathol Lab Med. 2020;144(8):920-928.

20. Alzamora MC, Paredes T, Caceres D, Webb CM, Valdez LM, La Rosa M. Severe COVID-19 during Pregnancy and Possible Vertical Transmission. Am J Perinatol. 2020;37(08):861-865.

21. Gajbhiye R, Modi D, Mahale S. Pregnancy outcomes, Newborn complications and Maternal-Fetal Transmission of SARS-CoV-2 in women with COVID-19: A systematic review. medRxiv. Published online May 2020:2020.04.11.20062356.

22. Poon LC, Yang H, Dumont S, et al. ISUOG Interim Guidance on coronavirus disease 2019 (COVID-19) during pregnancy and puerperium: information for healthcare professionals - an update. Ultrasound Obstet Gynecol. 2020;55(6):848-862.

23. Baergen RN, Heller DS. Placental Pathology in Covid-19 Positive Mothers: Preliminary Findings. Pediatr Dev Pathol. 2020;23(3):177-180.

24. Shanes ED, Mithal LB, Otero S, Azad HA, Miller ES, Goldstein JA. Placental Pathology in COVID-19. Am J Clin Pathol. 2020;154(1):23-32.

25. Smithgall MC, Liu-Jarin X, Hamele-Bena D, et al. Third-trimester placentas of severe acute respiratory syndrome coronavirus 2 (SARS-CoV-2)-positive women: histomorphology, including viral immunohistochemistry and in-situ hybridization. Histopathology. Published online September 2020:his.14215
26. Muldoon KM, Fowler KB, Pesch MH, Schleiss MR. SARSCoV-2: Is it the newest spark in the TORCH? J Clin Virol. 2020;127:104372.

27. Gro $\tilde{A} \ddot{Y}$ diger, Conzelmann C, Mã JA, et al. Detection of SARS-CoV-2 in human breastmilk. Lancet. 2020;395(10239):1757-1758.

28. Wang W, Xu Y, Gao R, et al. Detection of SARS-CoV-2 in Different Types of Clinical Specimens. JAMA. 2020;323:1843-1844.

29. Wong SF, Chow KM, Leung TN, et al. Pregnancy and perinatal outcomes of women with severe acute respiratory syndrome. Am J Obstet Gynecol. 2004;191:292-297.

30. Ng WF, Wong SF, Lam A, et al. The placentas of patients with severe acute respiratory syndrome: a pathophysiological evaluation. Pathology. 2006;38(3):210-218.

31. World Health Organization (WHO). Coronavirus Disease 2019 (COVID-19). World Health Organization (WHO); 2020

32. Mendoza M, Garcia-Ruiz I, Maiz N, et al. Pre-eclampsialike syndrome induced by severe COVID-19: a prospective observational study. BJOG An Int J Obstet Gynaecol. Published online June 2020:10.1111/1471-0528.16339.

33. Ribgy FB, Pastorek JG. Pneumonia During Pregnancy. Clin Obstet Gynecol. 1996;39(1):107-119.

34. Chen S, Liao E, Cao D, Gao Y, Sun G, Shao Y. Clinical analysis of pregnant women with 2019 novel coronavirus pneumonia. J Med Virol. 2020;92(9):1556-1561.

35. Baud D, Greub G, Favre G, et al. Second-Trimester Miscarriage in a Pregnant Woman with SARS-CoV-2 Infection. JAMA - J Am Med Assoc. 2020;323(21):21982200

36. la Cour Freiesleben N, Professor A, Egerup P, et al. SARSCoV-2 in first trimester pregnancy - does it affect the fetus? medRxiv. Published online June 2020:2020.06.08.20125195.

37. Amorim MMR, Soligo Takemoto ML, Fonseca EB da Maternal deaths with coronavirus disease 2019: a different outcome from low- to middle-resource countries? Am J Obstet Gynecol. 2020;223(2):298-299.

38. Takemoto MLS, Menezes M de O, Andreucci CB, et al. The tragedy of COVID-19 in Brazil: 124 maternal deaths and counting. Int J Gynaecol Obstet. Published online July 9, 2020

39. Deverman BE, Patterson PH. Cytokines and CNS Development. Neuron. 2009;64(1):61-78.

40. Lee DH, Lee J, Kim E, Woo K, Park HY, An J. Emergency cesarean section performed in a patient with confirmed severe acute respiratory syndrome Coronavirus- 2 -a case report-. Korean J Anesthesiol. 2020;73(4):347-351.

41. Yang Z, Wang M, Zhu Z, Liu Y. Coronavirus disease 2019 (COVID-19) and pregnancy: a systematic review. J Matern Fetal Neonatal Med. Published online April 30, 2020:1-4.

42. Shek CC, Ng PC, Fung GPG, et al. Infants born to mothers with severe acute respiratory syndrome. Pediatrics. 2003;112(4):e254. doi:10.1542/peds.112.4.e254

43. Brasil. Ministério da Saúde. Gerência de Vigilância e Monitoramento em Serviços de Saúde (GVIMS). Gerência Geral de Tecnologia em Serviços de Saúde (GGTES). 
Agência Nacional de Vigilância Sanitárária (ANVISA). Nota Técnica GVIMS/GGTES/ANVISA No 06/2020: Orientações Para a Prevenção e o Controle Das Infecções Pelo Novo Coronavírus (Sars-Cov-2) Em Procedimentos Orientações Para a Prevenção e o Controle Das Infecções Pelo Novo Coronavírus (Sars-Cov-2) Em Procedime. 2nd ed. Brasil. Ministério da Saúde.; 2020.

44. Stephens AJ, Barton JR, Bentum NAA, Blackwell SC, Sibai BM. General Guidelines in the Management of an Obstetrical Patient on the Labor and Delivery Unit during the COVID-19 Pandemic. Am J Perinatol. 2020;37(08):829-836.

45. Center of Disease Control and Prevention (CDC) Coronavirus Disease 2019 (COVID-19). Considerations for Inpatient Obstetric Healthcare Settings. Published 2020. Acessed August 20,2020. https://www.cdc.gov/coronavirus/2019-ncov/hcp/inpatient-obstetric-healthcare-guidance.html

46. American College of Obstetricians and Gynecologists (ACOG). Clinical Information. Physician FAQs. COVID19 FAQs for Obstetrician-Gynecologists, Obstetrics. Published 2020. Acessed August 20,2020. https://www.acog.org/clinical-information/physicianfaqs/covid-19-faqs-for-ob-gyns-obstetrics

47. World Health Organization (WHO). Clinical Management of COVID-19: Interim Guidance, 27 May 2020. World Health Organization (WHO); 2020.

48. Grobman WA, Rice MM, Reddy UM, et al. Labor Induction versus Expectant Management in Low-Risk Nulliparous Women. N Engl J Med. 2018;379(6):513-523.

49. Pasquier J-C, Claris O, Rabilloud M, et al. Intentional early delivery versus expectant management for preterm premature rupture of membranes at 28-32 weeks' gestation: A multicentre randomized controlled trial (MICADO STUDY). Eur J Obstet Gynecol Reprod Biol. 2019;233:3037.

50. Morris JM, Roberts CL, Bowen JR, et al. Immediate delivery compared with expectant management after preterm pre-labour rupture of the membranes close to term (PPROMT trial): A randomised controlled trial. Lancet. 2016;387(10017):444-452.

51. Crowther CA, Haslam RR, Hiller JE, Doyle LW, Robinson JS. Neonatal respiratory distress syndrome after repeat exposure to antenatal corticosteroids: a randomised controlled trial. Lancet. 2006;367(9526):1913-1919.

52. Murphy KE, Hannah ME, Willan AR, et al. Multiple courses of antenatal corticosteroids for preterm birth (MACS): a randomised controlled trial. Lancet. 2008;372(9656):2143-2151.

53. Chen D, Yang H, Cao Y, et al. Expert consensus for managing pregnant women and neonates born to mothers with suspected or confirmed novel coronavirus (COVID19) infection. Int J Gynecol Obstet. 2020;149(2):130-136.
54. Duley L. Do women with pre-eclampsia, and their babies, benefit from magnesium sulphate? The Magpie Trial: A randomised placebo-controlled trial. Lancet. 2002;359(9321):1877-1890

55. Favre G, Pomar L, Qi X, Nielsen-Saines K, Musso D, Baud D. Guidelines for pregnant women with suspected SARSCoV-2 infection. Lancet Infect Dis. 2020;20(6):652-653.

56. Pfeifer M, Ewig S, Voshaar T, et al. Position Paper for the State-of-the-Art Application of Respiratory Support in Patients with COVID-19. Respiration. 2020;99(6):521-542.

57. Center of Disease Control and Prevention (CDC). Coronavirus Disease 2019 (COVID-19). Interim Infection Prevention and Control Recommendations for Healthcare Personnel During the Coronavirus Disease 2019 (COVID19) Pandemic.Published 2020. Acessed August 20,2020.https://www.cdc.gov/coronavirus/2019ncov/hcp/infection-control-recommendations.html

58. Amorim MMR, Melo ASO, Oliveira T V, França Neto AH Protocolo de Atencimento de Pacientes Com COVID-19 (Infecção Suspeita Ou Confirmada). (Sales LMS, ed.). Instituto de Saúde Elpídio de Almeida (ISEA); 2020.

59. Associação Médica Intensivista Brasileira (AMIB), 2020.https://www.amib.org.br/fileadmin/user_upload/amib/ 2020/marco/07/COVID-

19_seguranca_equipev14032020_18h16.pdf.

60. Center for EvidenceBased Medicine (CEBM), 2020. https://oxfordbrazilebm.com/index.php/comentarios-doeditor-revisoes-rapidas-sobre-epi-uma-atualizacao/

61. RCOG. Information for Healthcare Professionals Coronavirus (COVID-19) Infection in Pregnancy. Royal College of Obstetricians and Gynaecologists (RCOG); 2020.

62. Zeng H, Xu C, Fan J, et al. Antibodies in Infants Born to Mothers With COVID-19 Pneumonia. JAMA. 2020;323(18):1848-1849.

63. Barton JR, Sibai BM. Severe sepsis and septic shock in pregnancy. Obstet Gynecol. 2012;120(3):689-706

64. Ankumah NAE, Blackwell SC, Alrais MA, et al. Liberal versus Indicated Maternal Oxygen Supplementation in Labor: A Before-and-After Trial. Am J Perinatol. 2018;35(11):1057-1064

65. Coronavirus disease 2019 (COVID-19): Pregnancy issues UpToDate. Accessed July 24, 2020. https://www.uptodate.com/contents/coronavirus-disease2019-covid-19-pregnancy-issues

66. Departmentof Health (2019). IMEWS (NCEC National Clinical Guideline No. 4 Version 2). Availableat:http://health.gov.ie/national-patient-safetyoffice/ncec/

Received on September 29, 2020

Approved on December 7, 2020 